\title{
REDES SOCIAIS: UM ESTUDO DE CASO SOBRE A FAZENDA DA ESPERANÇA
}

\author{
Antonio Gomes Galvez ${ }^{1}$ \\ Denise Pena de Moraes ${ }^{2}$ \\ Denise Perroud Amaral ${ }^{3}$ \\ Joelson Alves do Nascimento ${ }^{4}$ \\ Marisa Gianetti ${ }^{5}$
}

\section{Resumo}

Este artigo trata de um estudo de caso sobre a Fazenda da Esperança, entidade filantrópica sem fins lucrativos, que tem por objetivo a recuperação de tóxicodependentes, fundamentada na tríade: convivência, laborterapia e prática da espiritualidade, e cujas ações nas áreas da Assistência Social, Saúde e Educação tem promovido uma transformação social dos atores envolvidos. O artigo apresenta uma pesquisa sobre a contribuição das redes na solução das questões sociais, uma vez que essas ocupam a lacuna criada pelo afastamento do Estado nesta problemática. A Fazenda da Esperança foi criada a partir de ações individuais e consolidou-se na estruturação de uma rede hierarquizada, baseada nas relações de confiança estabelecidas entre os diversos atores que compartilhavam o interesse em responder ao problema das drogas na comunidade, permitindo a criação de articulações entre as diversas organizações: públicas, privadas e do terceiro setor de forma a contribuir com a gestão das políticas sociais. Como resultados deste estudo, destacam-se: a identificação das inter e intrarelações da Fazenda da Esperança com a comunidade e parceiros e a formação de laços fortes e fracos, revelando um importante elemento de inovação no atendimento das necessidades sociais. Finalmente apontam-se novas possibilidades de temas para pesquisa visualizando as relações em rede e suas conseqüências.

\footnotetext{
${ }^{1}$ Graduado em Administração de Empresas pela Pontifícia Universidade Católica de São Paulo. Atualmente é Mestrando em Administração pela Pontifícia Universidade Católica de São Paulo.

${ }^{2}$ Mestranda em Administração de Empresas pela Pontifícia Universidade Católica de São Paulo, pósgraduada em Marketing pela Fundação Getúlio Vargas, e graduada em Comunicação Social, com especialização em Marketing, pela Escola Superior de Propaganda e Marketing.

${ }^{3}$ Graduada em Serviço Social pela Pontifícia Universidade Católica de São Paulo. Atualmente cursa o mestrado do Programa de Pós Graduação em Serviço Social da PUC/SP sendo membro efetivo do Núcleo de Estudos e Pesquisa em Saúde e Sociedade desta instituição.

${ }^{4}$ Graduado em Administração com Habilitação em Comércio Exterior pela Universidade Mackenzie. Atualmente sou Mestrando em Administração pela PUC - Pontifícia Universidade Católica de São Paulo.

${ }^{5}$ Graduada em Economia pela Pontifícia Universidade Católica de São Paulo e especialista em Gestão de Tecnologia da Informação pela Faculdade de Informática e Administração Paulista - FIAP.
}

Artigo recebido em Novembro de 2009 e aceito em Fevereiro de 2010.

Revista Administração em Diálogo

Programa de Estudos Pós-Graduados em Administração

Pontifícia Universidade Católica de São Paulo 
Palavras-chave: redes sociais, políticas sociais, laços fortes e fracos, Fazenda da Esperança, tóxico-dependência.

\begin{abstract}
This article is a case study on the Farm of Hope, a non-profit filantropic entity that aims at recovering drug addicts, based on 3 fundamental elements: sharing common space, work and practice of spirituality, and whose actions in the areas of Social Assistance, Health and Education have promoted a social transformation of the actors involved. The article presents a study on the contribution of networks in the solution of social issues, since these occupy the void created by the withdrawal of the State on this issue. The Farm of Hope was created out of individual actions and consolidated itself in the structure of a hierarchical network, based on established trust relationships between the various actors who shared an interest in responding to the drug problem in the community, allowing the creation of joint between the various organizations: public, private and nonprofit in a way to contribute to the management of social politics. As results of this study, we have: the identification of internal and external relationships of Farm of Hope with the community and partners and the formation of strong and weak ties, revealing an important element of innovation in meeting social needs. Finally it was pointed out new possibilities of topics for research by viewing the relationships in the network and its consequences.
\end{abstract}

Key words: social networks, social politics, strong and weak ties, Farm of Hope, drug addiction.

\title{
Introdução
}

$\mathrm{Na}$ linha do Neoliberalismo, onde o progresso da humanidade dar-se-ia de forma inevitável, a partir do livre mercado [43], no caso do Brasil, principalmente a partir da década de 90, o afastamento do Estado na solução das questões sociais pode ser explicado pelo esforço do governo no combate à inflação e estabilidade da moeda, implementando políticas sociais subordinadas à orientação macroeconômica [41] por meio de ações focalizadas, onde o gasto social foi direcionado à programas e públicosalvo específicos, seletivamente escolhidos pela sua maior necessidade e urgência em detrimento de uma política social nacional. Essa estratégia implica na dificuldade dos governos em atender as garantias dos direitos individuais de acesso, principalmente à saúde, educação e moradia, na medida em que são priorizadas ações pontuais para suprir essas necessidades básicas, gerando uma carência nas populações em situação de

\footnotetext{
Revista Administração em Diálogo

Programa de Estudos Pós-Graduados em Administração Pontifícia Universidade Católica de São Paulo
} 
exclusão e aumento da complexidade dos problemas sociais. O cenário contemporâneo configura-se pela urgência de respostas às necessidades sociais, por outro lado apresentam-se oportunidades de novas articulações entre as diversas organizações: públicas, privadas e do terceiro setor na gestão das políticas sociais para a redução da pobreza e fortalecimento da democracia nas sociedades [33].

Nesse contexto, a sociedade assume junto ao Estado a busca de parte das soluções para respostas às suas necessidades por meio de novas configurações, com atores sociais articulados em rede, contribuindo para o aumento da eficiência da gestão pública e social. A formação de redes sociais inter e intraorganizacionais [i] constitui-se como um importante elemento de inovação na gestão das políticas sociais, por possibilitar respostas intersetoriais. Junqueira [18] explica que "ao invés de estabelecer parcerias isoladas por políticas, muda-se a lógica, ou seja, identificam-se os problemas sociais, integrando saberes e experiências das diversas políticas, passando a população também a desempenhar um papel ativo e criativo nesse processo".

Entidades filantrópicas têm surgido e firmado sua atuação como importantes atores na luta pelas causas sociais e na transformação de indivíduos, contribuindo para o resgate da cidadania. Portanto, abre-se a possibilidade de estudar um dos atores sociais e o seu papel na participação do panorama das políticas sociais na transformação da sociedade.

Tendo em vista a contribuição das redes na solução das questões sociais e a crescente produção acadêmica sobre este tema, mostrou-se oportuno fazer uma análise sobre sua formação, com o objetivo de identificar as relações em uma entidade do terceiro setor. Para este estudo, devido ao seu impacto social no atendimento de jovens e adultos dependentes químicos, foi escolhida a Fazenda da Esperança, entidade filantrópica sem fins lucrativos. Essa entidade faz parte de uma rede descentralizada, formada a partir de um contexto nacional e internacional, que tem por objetivo a recuperação de tóxicodependentes, por meio de ações intersetoriais que incorporam iniciativas das áreas da Assistência Social, Saúde e Educação.

\footnotetext{
Revista Administração em Diálogo 
Esse objetivo foi capaz de aglutinar alguns atores sociais que tinham motivações semelhantes, dando origem ao processo de constituição da Fazenda da Esperança. Sua expansão deve-se ao crescente afastamento do Estado nas soluções das questões sociais e na complexidade da sociedade em lidar com a problemática da dependência química. A parceria que se estabeleceu primeiramente nas relações interpessoais extrapolou para relações interinstitucionais, preservando as diferenças e as especificidades de cada "nó" [ii] dessa rede.

Assim, investigou-se como as redes sociais se configuram e se sustentam nesta instituição de reconhecido perfil social no terceiro setor, que define como prioridade a busca da recuperação de dependentes químicos através de uma forma de organização inovadora, vencendo barreiras de aproximação, convivência, reciprocidade, buscando multiplicar os efeitos positivos de suas ações através de várias unidades no Brasil e no exterior.

\section{Histórico da Fazenda da Esperança}

A Fazenda da Esperança é uma comunidade terapêutica de recuperação de tóxicodependentes e alcoolistas. Seu trabalho é desenvolvido de modo particular na convivência entre os dependentes e na apresentação de um novo estilo de vida. Dessa forma não se prioriza o uso de medicamentos e psicoterapia e busca-se trazer os dependentes, que não possuem em sua grande maioria laços afetivos, para uma nova realidade, uma nova forma de organização, com o objetivo de vencer barreiras de aproximação com seus pares, inicialmente, baseando-se em experiências, convivência, reciprocidade, redescoberta do valor do ser humano, retomada da dignidade, através de trabalhos e práticas espirituais. $\mathrm{O}$ início da recuperação dá-se pela própria vontade do dependente que deve expressar-se através de uma carta à instituição, mostrando seu desejo explícito em recuperar-se.

O processo caracteriza-se na descoberta de si mesmo, do seu potencial e do relacionar-se a serviço dos outros, e portanto, dos iguais. A partir da experiência vivenciada pelos

\footnotetext{
Revista Administração em Diálogo Programa de Estudos Pós-Graduados em Administração Pontifícia Universidade Católica de São Paulo
} 
pares, do trabalho e da convivência numa comunidade que se espelha no relacionamento de família, onde os membros ajudam-se a amadurecer no respeito recíproco e no afeto, os dependentes retornam à sociedade transformados. Neste processo é normal e salutar que ocorram embates, os quais são tratados individualmente.

A Fazenda atende jovens e adultos na faixa etária entre 15 e 45 anos, moças e rapazes, em unidades separadas por sexo. Os dependentes são acomodados em pequenas casas numa fazenda, em grupos de 7 à 10 pessoas, sempre acompanhados por um líder, que é um recuperado ou recuperando em fase final, dando o peso da responsabilidade e compromisso com a proposta da instituição. Organizam-se nesses locais para o convívio em grupo, o exercício laboral e a prática espiritual. A estrutura da instituição inclui também unidades de apoio, escritórios e pequenas fábricas localizadas dentro e fora dessas fazendas.

Segundo a própria instituição, o sucesso obtido na recuperação dos jovens (aproximadamente 80\%) fez com que a Fazenda da Esperança crescesse, chegando, em julho de 2007, a 26 centros masculinos e 11 femininos somente nos estados brasileiros. A expansão da Fazenda da Esperança no exterior tem ocorrido devido à dificuldade da sociedade global em lidar com a complexidade da problemática da dependência química. A Fazenda encontra-se instalada nos seguintes países: Alemanha, Guatemala, Argentina, Paraguai, México, Itália, Filipinas, Moçambique, Angola e Rússia, estando em processo de avaliação novos pedidos de abertura.

O trabalho é realizado por pessoas voluntárias, pessoas consagradas da igreja (sacerdotes, leigos consagrados, freiras e frades), ex-dependentes e suas famílias, famílias constituídas dentro e fora da instituição e empregados, entre outros.

As iniciativas desenvolvidas pela Fazenda da Esperança extrapolam a recuperação dos dependentes. Alguns projetos puderam ser identificados pelo grupo: projeto de moradia para famílias carentes, creches, atividades sócio-educativas para crianças, adolescentes e

\footnotetext{
Revista Administração em Diálogo

Programa de Estudos Pós-Graduados em Administração Pontifícia Universidade Católica de São Paulo
} 
mães em risco social, reciclagem de lixo inorgânico, posto médico e odontológico, casa de apoio para crianças vitimas de maus tratos e em situação de rua, casa de apoio à pacientes com HIV-Aids, projeto de arte, bazar, livraria, mídia e grupo Esperança Viva.

O grupo Esperança Viva é composto de recuperados, famílias, voluntários e jovens em fase de espera para iniciar o tratamento em alguma fazenda, espalhados em diversas unidades pelo Brasil e exterior, tornando-se uma ação facilitadora para a formação e reprodução de redes sociais a partir de encontros na comunidade local. Esse grupo, além de levar a realidade da comunidade terapêutica para a sociedade, tem estimulado os jovens a manterem-se de "cara limpa", com isso, muitos desses têm tido a possibilidade de se recuperar nesses grupos antes de adentrar na Fazenda.

O projeto "Viver de Cara Limpa - Uma Escolha" tem por objetivo, tratar do tema das drogas falando abertamente com os jovens em escolas e outros ambientes, a partir da consciência de que o seu consumo é uma das grandes chagas da sociedade atual. O combate ao uso de drogas é tratado a partir da perspectiva da escolha e não da proibição. É nesse conceito, e a partir da história real de um ex-recuperando, ex-usuário de drogas da periferia de São Paulo, que se baseia o projeto.

O trabalho desenvolvido pela Família Esperança, uma associação de fiéis de berço católico com base no carisma da pobreza dos franciscanos e o carisma da unidade do Movimento dos Focolares, mantém a Fazenda atuante no Brasil e no mundo.

Conforme explicitado, a instituição tem como objetivos: a ampliação do número de pessoas atendidas com a abertura de novas unidades e novas formas de auto-sustentação; a formação e capacitação de voluntários e funcionários; a melhoria contínua da qualidade do atendimento; a criação de novos espaços de lazer e esporte; o estabelecimento de parceria com outras entidades; a integração assegurada dos diversos setores de atendimento da entidade à sua visão; o fortalecimento do processo de reinserção dos recuperandos, aumentando o número de grupos de auto-ajuda "Esperança Viva",

\footnotetext{
Revista Administração em Diálogo

Programa de Estudos Pós-Graduados em Administração

Pontifícia Universidade Católica de São Paulo
} 
formando sua liderança através da Secretaria Central, dos comitês nacional e regional; a estruturação de Casas de Apoio aos dependentes e ex-dependentes químicos e alcoólicos; o aperfeiçoamento e ampliação do atendimento às crianças vítimas do vírus HIV com a colocação em famílias substitutas; a implantação de uma clínica de atendimento psicológico para atendimento dos recuperandos, suas famílias, voluntários e a comunidade local; o aumento da divulgação da visão, experiência e metodologia da entidade, realizando eventos com temas de prevenção dentro e fora da Fazenda; aperfeiçoamento do material a ser exposto e construção de novas estruturas; dar resposta aos problemas sociais e contribuir para que se realize o desejo de Jesus: "Para que todos sejam um, como tu, ó Pai, o és em mim, e eu em ti” [3].

Em função dos vários projetos sociais desenvolvidos, através das Obras Sociais e de seus "braços sociais", a Fazenda da Esperança mantém forte relação com os atores relacionados: comunidade local no desenvolvimento de atividades e prestação de serviços, recebimento de doações, formação de voluntários, etc.; empresários através de parcerias e doações; poder público nas esferas municipal, estadual e federal, através de subvenções para o desenvolvimento de atividades, prestação de serviços, termos de parceria e Igreja.

\section{Metodologia}

A pesquisa é um estudo de caso de natureza qualitativa. A pesquisa qualitativa trabalha com o universo de significados, motivos, aspirações, valores e atitudes, o que corresponde a um espaço mais profundo das relações, dos processos e dos fenômenos que não podem ser reduzidos a operacionalização de variáveis [26]

Tal abordagem possibilitou o estudo da Fazenda e suas relações, reunindo informações, que permitiu aprender sobre a formação e as relações na Fazenda da Esperança e entender a complexidade das relações em rede.

\section{Coleta de dados}

Revista Administração em Diálogo Programa de Estudos Pós-Graduados em Administração Pontifícia Universidade Católica de São Paulo 
a) Para realizar esta pesquisa foram levantados documentos da Fazenda da Esperança, tais como: livros, Estatutos, Relatório Geral, dvds institucionais, sites da Fazenda da Esperança e da Prefeitura Municipal de Guaratinguetá e catálogo do circuito turístico-religioso do SEBRAE-SP;

b) Entrevistas em profundidade com pessoas-chave identificadas na Fazenda da Esperança nas unidades de Guaratinguetá/SP (Fundadores, Diretor de Marketing e Comunicação Institucional, Gerente Financeiro e Contábil, Gerente da Fábrica de Reciclagem, Responsável da Fazenda em Pedrinhas, Gerente de Atendimento aos Dependentes Químicos e Diretora da Creche São Manuel);

c) Entrevista em profundidade com pessoas-chave identificadas na comunidade da cidade de Guaratinguetá/SP, com representantes da Igreja local (Pároco e Religiosos) e com representante do poder público local (Engenheiro da Secretaria do Meio Ambiente);

d) Observação participante em unidades da Fazenda da Esperança em Guaratinguetá/SP.

\section{A abordagem de redes e a busca de soluções para os problemas sociais decorrentes da tóxico-dependência}

Apesar de ser um tema relevante na atualidade, os conceitos e aplicações de redes datam desde a década de 30 e desde então vêm tornando-se fenômenos sociais proeminentes. No Brasil, as tendências de estudo das redes sociais e as práticas relacionadas têm um acúmulo mais significativo nas ciências humanas e sociais, embora permeie todas as áreas do conhecimento.

Consideradas centrais na sociabilidade dos indivíduos, as redes estruturaram-se sistemicamente pelas relações sociais que envolvem principalmente indivíduos, grupos e

Revista Administração em Diálogo Programa de Estudos Pós-Graduados em Administração Pontifícia Universidade Católica de São Paulo 
organizações, sujeitos sociais, que são os "nós" das redes, conduzindo para uma transformação da organização social. A sociedade atual contribui para a instabilidade, a evolução e a flutuação das relações sociais [29], que reforçam a reprodução do comportamento do tóxico-dependente, sendo que para o processo de recuperação das drogas é necessária a desconstrução da realidade que privilegia a repetição, a regularidade e a estabilidade social do seu contexto.

O conceito de rede social utilizado nesse estudo parte de um pressuposto da sociologia relacional, presente no texto de Emirbayer [8], pelo enfoque central nas relações sociais. Assim, na análise da constituição da Fazenda da Esperança, verificou-se que as relações iniciais interferiram na formação da sua estrutura, nas posições dos atores, nas inter e intrarelações existentes, bem como, conformaram suas ações e estratégias para alcançar o objetivo final, a recuperação dos tóxico-dependentes.

As relações de amizade e confiança existentes entre o pároco da igreja Nossa Senhora da Glória, Frei Hans, e Nelson, jovem paroquiano, através de um novo estilo de vivenciar concretamente o evangelho, permitiram que estes acolhessem os jovens tóxicodependentes da esquina, ponto de encontro até aquele momento para o uso de drogas. As relações espontâneas com os dependentes químicos resultaram num pedido ao Nelson para sair da dependência das drogas, originando a formação da Fazenda da Esperança.

Nessa perspectiva, a sociedade moderna é caracterizada pela predominância da forma organizacional da rede em todos os campos da vida social e está sujeita, conforme apontado por Castells [5] às modificações de maneira significativa da operação e resultados dos processos produtivos e de experiência, poder e cultura. Essa experiência de recuperação acontece por meio do tripé: convivência, trabalho e espiritualidade, que se dá pela partilha da vida quotidiana, pelo trabalho como possibilidade de reconstruir a dignidade individual e coletiva, além da necessidade do auto-sustento e ocupação e pela descoberta da vida interior, na perspectiva de vivência do evangelho.

Revista Administração em Diálogo Programa de Estudos Pós-Graduados em Administração Pontifícia Universidade Católica de São Paulo 
Esta rede, entendida como uma nova morfologia social, mostrou-se componente fundamental das relações dos sujeitos sociais capazes de formar-se e expandir-se pela criação de novos relacionamentos a partir de experiências compartilhadas. $\mathrm{O}$ compartilhamento da experiência espiritual e a presença das Clarissas [iii], em colaboração com a Fazenda da Esperança, contribuem para fortalecer o processo de recuperação das drogas. A expansão realizada por meio de interações e vínculos propiciou uma mudança concreta na vida dos sujeitos empenhados na ação comum ao objetivo co-responsabilizado, mantendo suas particularidades preservadas. Nessa perspectiva, as relações sociais estabelecidas foram somadas à participação do poder público, das organizações da sociedade civil, das empresas e voluntários. Nesse sentido, a análise de Junqueira [19] veio ao encontro da rede problematizada por inferir que as redes são construídas por seres sociais autônomos que compartilham objetivos, respeitando a autonomia e as diferenças de cada membro. Daí a importância de cada organização pública, seja estatal ou privada, desenvolver seu saber para colocá-lo de maneira integrada a serviço do interesse coletivo.

O aprofundamento na análise da formação da Fazenda da Esperança remete aos conceitos de rede social informal, uma vez que esta surgiu sob uma demanda subjetiva, na medida em que teve início a partir da visão pessoal dos protagonistas do movimento que deu origem à Fazenda, e demanda de necessidade, em função da primeira demanda da comunidade local, diante da complexidade da sociedade em lidar com a problemática da dependência química. As conexões interpessoais estabelecidas inicialmente entre a comunidade local e a Igreja (sacerdotes, leigos consagrados, freiras e frades) na vida cotidiana do município de Guaratinguetá/SP foram decisivas na formação desta rede para os dependentes químicos e suas famílias. Nos estudos sobre redes sociais, observou-se que é dada ênfase às relações informais, em detrimento das estruturas hierárquicas. $\mathrm{O}$ trabalho produzido através de redes de relações informais foi o resultado da forma de articulação dos indivíduos presentes no cotidiano das organizações que formaram diferentes níveis de estruturação desta rede [24].

\footnotetext{
Revista Administração em Diálogo Programa de Estudos Pós-Graduados em Administração Pontifícia Universidade Católica de São Paulo
} 
A mediação de novas tecnologias de informação, apesar de não ser uma característica comum a todas as redes, mostrou-se significativamente presente na Fazenda. A comunicação aprimorada nos últimos anos facilitou a tomada de decisão e a organização das atividades nos diversos pontos da rede social. No entanto, as redes sociais, entendidas como espaço de troca de conteúdo, não envolvem somente a transferência de artigos como informação, mas sentimentos, conselhos, ou coisas mais tangíveis como bens e serviços. O estudo de caso escolhido vislumbrou também a troca de experiências partindo da convivência entre os vários atores envolvidos.

As conexões estabelecidas inicialmente nesta rede por meio de relacionamentos sociais e de forma espontânea foram motivadas principalmente pela amizade, convivência e compartilhamento do interesse em responder ao problema das drogas na comunidade. $\mathrm{O}$ sucesso inicial, obtido na estratégia de recuperação dos tóxico-dependentes, permitiu a expansão da rede que evoluiu para uma rede não-espontânea, já que definiu institucionalmente o objetivo de recuperação pelo formato padrão de um local organizado para o convívio em grupo, o exercício laboral e a prática espiritual. De certa forma mostrou-se como uma rede evolutiva.

A necessidade de resolver a complexidade dos problemas sociais provenientes das drogas mobilizou diversos atores em torno de outros temas pertinentes com intuito de reforçar a colaboração e a solidariedade, a fim de dar resolutividade aos vários problemas sociais, criando uma "rede de ações sociais específicas". A estrutura e a dinâmica desta rede evolutiva, formada a partir do perfil socioassistencial da Igreja e comunidade, extrapolou o objetivo inicial de recuperação de tóxico-dependentes para a inclusão social de diversos segmentos vulneráveis, agregando à Obra Social, outros vínculos para uma articulação intersetorial. Foram considerados projetos de moradia para famílias carentes, creches, atividades socioeducativas para crianças, adolescentes e mães em risco social, reciclagem de lixo inorgânico, posto médico e odontológico, casa de apoio para crianças vítimas de maus tratos e em situação de rua e casa de apoio para pacientes com HIV-Aids.

Revista Administração em Diálogo 
Por outro lado, o potencial de intervenção desta rede propiciou em sua evolução articulações sócio-demográficas, do local ao global, devido à complexidade da sociedade global em lidar com a problemática da dependência química.

Nesse panorama, a ênfase de Fleury e Overney [10] na rede como uma solução para administrar políticas e projetos onde os recursos são escassos e os problemas complexos, onde existem múltiplos atores envolvidos, onde há interação de agentes públicos e privados, centrais e locais, bem como uma crescente demanda por benefícios e participação cidadã, mostrou-se pertinente.

Verificou-se que algumas das seguintes características das redes sociais destacadas por Fleury e Overney [10] estão presentes na rede estudada: a participação de vários atores que possibilita uma maior mobilização por recursos e uma diversidade de olhares para a tomada de decisão; a definição de prioridade ocorre de forma democrática; a estrutura mostra-se flexível e menos burocrática. A gestão da Fazenda da Esperança ocorre com o compartilhamento das responsabilidades entre os diversos atores que contribuem individualmente, através da participação nas Diretorias Geral e Local, facilitando as definições estratégicas da entidade.

Se por um lado, a organização menos formal dessa rede traz aspectos positivos, como resultados efetivos na solução das questões sociais envolvendo não somente a recuperação dos jovens, mas também a inclusão social de suas famílias, por outro lado apresenta certos limitadores que devem ser objeto de atenção: dificuldades na prestação de contas e elaboração dos relatórios obrigatórios para atender à legislação decorrente do caráter filantrópico da entidade; lentidão nas tomadas de decisão resultante da forma de articulação dos atores nessa rede, cujo poder é centralizado, mas também pode ser exercido individualmente e por fim um processo de comunicação interna desestruturado que dificulta a integração de todos os atores na ação coletiva. Ainda assim, recuperando a idéia de Siqueira [37], identificou-se muito mais fatores favoráveis que contrários à utilização desta rede para a solução dos problemas sociais, pois a rede da Fazenda 
apresenta como característica fundamental o desenvolvimento de aprendizado social para respostas adaptativas com melhores resultados que outras formas organizacionais.

\section{As relações da Fazenda da Esperança}

A partir da definição dos papéis, atribuições e relações entre seus atores, a rede da Fazenda passou por processo de estruturação, hierarquização e externalização e dispõe de parcerias que passam a assumir, em caráter complementar, as ações sociais que possibilitam oferecer à população local respostas às suas necessidades sociais, por exemplo, o enfrentamento da precária condição de vida pelo uso das drogas. Os atores estabelecem relações de longo prazo ao se organizarem em torno de um objetivo comum, conforme observado no trabalho de Hakanson [15].

A formação de redes sociais inter e intra-organizacionais da Fazenda constitui importante elemento de inovação na gestão das políticas sociais direcionadas ao foco de tóxicodependência, por possibilitar respostas intersetoriais, principalmente das áreas de Assistência Social, Saúde e Educação, bem definidas nos projetos que integram a rede vislumbrada.

Junqueira [18] contribui para entender a importância da participação da população que passa a desempenhar um papel ativo e criativo no processo de construção das ações intersetoriais dessa rede, pela presença do voluntariado local e da pressão que a comunidade exerce junto ao poder público. $\mathrm{O}$ alcance do objetivo comum na rede da instituição é possibilitado pela participação voluntária da comunidade, como pode ser observado pela presença individual e/ou de famílias no desenvolvimento de atividades com os recuperandos.

\footnotetext{
Revista Administração em Diálogo Programa de Estudos Pós-Graduados em Administração Pontifícia Universidade Católica de São Paulo
} 
Percebe-se que responsáveis e recuperandos da Fazenda são comprometidos com o tratamento de desintoxicação. $\mathrm{O}$ fato da adesão ao programa ser espontânea permite o trânsito livre e a abertura dos portões da Fazenda, o que denota a confiança como aspecto fundamental dessa relação.

Pode-se dizer, portanto, que com o crescimento das organizações do terceiro setor, as redes sociais têm adquirido grande importância na última década, principalmente porque surgem como opção de mudança e também como possibilidade de propiciar maior eficácia à gestão pública das políticas sociais. Essas organizações surgiram na esteira de uma nova conjuntura social, em que a complexidade dos problemas impõe soluções eficazes e efetivas para reduzir a exclusão social e construir uma sociedade mais justa e equânime [21].

Para aprofundar o estudo das redes sociais faz-se necessário remeter à análise de Granovetter [13] sobre laços fortes e laços fracos. A imersão social (embeddedness), na perspectiva de Granovetter explica como os indivíduos não agem de maneira autônoma, pois suas ações estão imersas em um sistema concreto e contínuo de relações sociais. Neste contexto, a paróquia exerceu papel de ligação da sociedade local com a estrutura da Igreja Católica.

Analisar a Fazenda da Esperança sob a ótica da imersão social evidencia a relação do indivíduo com universos sociais distintos. É fácil identificar, por exemplo, as relações pessoais mais imediatas do indivíduo, laços fortes (família, amigos, etc.) e as relações mais afastadas, laços fracos (conhecidos).

Para Granovetter [13], os laços diferenciam-se pela função e pelos vínculos. Para sustentar a coesão comunitária e a ação coletiva os vínculos fortes, significando relações interpessoais de parentesco e amizade íntima, são menos importantes do que os fracos, identificados como conhecimentos e afiliação a associações secundárias. Nesse sentido, os vínculos fracos têm maior probabilidade de unir membros em pequenos grupos

\footnotetext{
Revista Administração em Diálogo Programa de Estudos Pós-Graduados em Administração Pontifícia Universidade Católica de São Paulo
} 
diferentes do que os vínculos fortes. Conforme constatado no histórico da formação da rede da Fazenda, os vínculos fracos estabelecidos entre os membros de uma mesma paróquia resultaram em relações sociais direcionadas para empreender a coesão comunitária na recuperação de tóxico-dependentes que ali conviviam. Foi através da relação de laços fracos que, por meio de um paroquiano, houve a primeira doação de terreno para a Fazenda da Esperança.

As redes sociais acionadas para provisão de recursos nas mais diversas áreas das políticas sociais de acordo com Portugal [27], também colaboraram neste estudo por verificar que para algumas ações a rede é acionada, bem como são ativados os laços que melhor respondem às necessidades da Fazenda. Neste caso, para atender uma necessidade dos tóxico-dependentes e suas famílias, criou-se uma parceria entre a Fazenda e uma clínica de psicologia. Deste modo, para obtenção de recursos a Fazenda centra-se nos laços fortes e em outros momentos nos laços fracos, essenciais para garantir a provisão das necessidades sociais dos seus membros.

A produção de água sanitária em uma das unidades da Fazenda é uma forma de alavancar recursos para sua sustentabilidade econômica conforme estudo sobre arranjos organizacionais e laços sociais realizado por Baldi e Lopes [2].

Essa relação revela a existência e a intensidade dos seus laços e a influência dos fatores sócio-culturais na formação de arranjos organizacionais, permitindo que ocorra a associação com os núcleos internacionais da Fazenda que tiveram origem em decorrência dos resultados positivos na recuperação dos tóxico-dependentes.

\section{Considerações Finais}

Redes sociais, tema desse trabalho, têm sido uma preocupação crescente na produção acadêmica por possibilitar respostas efetivas às questões sociais. Foi estudada a Fazenda da Esperança, por constituir uma rede social que estabelece relações com diversos atores:

\footnotetext{
Revista Administração em Diálogo Programa de Estudos Pós-Graduados em Administração Pontifícia Universidade Católica de São Paulo
} 
poder público, organizações da sociedade civil, empresas, comunidade local, voluntários, funcionários, Igreja (sacerdotes, leigos consagrados, freiras e frades), voltados para a recuperação de dependentes químicos e suas famílias na cidade de Guaratinguetá/SP.

As conexões interpessoais estabelecidas inicialmente entre a comunidade local e a Igreja na vida cotidiana do município foram permeadas por relacionamentos espontâneos, amizade, convivência e compartilhamento do interesse em responder ao problema das drogas na comunidade, tendo sido decisivas para a criação desta rede. Os vínculos criados entre os membros da paróquia Nossa Senhora da Glória resultaram em relações sociais que favoreceram a coesão comunitária no processo de inclusão desses jovens.

A Fazenda da Esperança adequou sua estrutura às mudanças nas inter e intrarelações existentes entre os atores, conformando suas ações e estratégias para alcançar seu objetivo, qual seja, a recuperação dos tóxico-dependentes.

A estrutura e a dinâmica desta rede resultaram da articulação inter-setorial a partir da demanda não só dos tóxico-dependentes como também de outras atividades de apoio aos diversos segmentos vulneráveis da sociedade. Assim as iniciativas desenvolvidas pela rede extrapolam a recuperação dos dependentes e incorporam outros projetos sociais para solução das condições de vida decorrentes das drogas.

A utilização de novos meios de comunicação nos últimos anos também foi decisiva para a expansão da rede, colaborando na mudança concreta das relações da Fazenda com os recuperandos, suas famílias, e influenciando de forma mais abrangente o público externo.

A metodologia de tratamento baseado no tripé do convívio em grupo, o exercício laboral e a prática espiritual, que ocorrem em um mesmo espaço e com o mesmo objetivo, revela a força dos laços fracos na medida em que a rede é potencializada por meio das interações entre os participantes da Fazenda.

Revista Administração em Diálogo 
O tema redes sociais, mencionado nesse trabalho, abre outras possibilidades de pesquisa: respostas às questões identificadas na rede da Fazenda (dificuldade na prestação de contas, lentidão das decisões decorrentes da busca por consenso e processo de comunicação interna desestruturado); estudo sobre as relações de poder na rede da Fazenda da Esperança (igreja, comunidade local, poder público, tóxico-dependentes e seus familiares); a ampliação do estudo das relações da Fazenda, no estado de São Paulo com as demais unidades no Brasil e no exterior, para entender como acontece a formação de redes em realidades culturais diferentes e seus desdobramentos, e também a investigação sobre redes como um processo de empoderamento e mudança social. Além disso, é relevante entender as relações da Fazenda com o mercado e os processos que surgem em função da confiança gerada nessas relações.

\section{Notas}

[i] Interorganizacional: entende-se como as interações entre empresas e suas nuances, como a noção de cadeia/sistema. Intraorganizacional: entende-se como as relações no âmbito interno da empresa.

[ii] Nó: entende-se "nó" todo individuo ou organização que aparece na rede como um dos seus atores centrais.

[iii] Clarissas: ordem das religiosas ligadas à espiritualidade de Santa Clara de Assis.

\section{Referências}

[1] Arendt, H., A condição humana, São Paulo, Forense/Edusp, 1981:212.

[2] Baldi, M., Lopes, F. D., Laços sociais e formação de arranjos organizacionais cooperativos - proposição de um modelo de análise, In RAC - Revista de Administração Contemporânea, abr./jun. 2005, 9(2): 81-101.

[3] Bíblia, São João, A Bíblia Sagrada: o velho e o novo testamento, Tradução de João Ferreira de Almeida, Edição Revista e Corrigida, Barueri - SP: Sociedade Bíblica do Brasil, 1969, cap.17, ver.21.

[4] Cândido, G. A., Goedert, A., Abreu, A. F., Os conceitos de redes e as relações interorganizacionais: um estudo exploratório. In: ENANPAD, 2000. Florianópolis: Anais, Florianópolis: ANPAD, 2000, $1^{\circ} \mathrm{CD}$.

\footnotetext{
Revista Administração em Diálogo

Programa de Estudos Pós-Graduados em Administração Pontifícia Universidade Católica de São Paulo
} 
[5] Castells, M., A sociedade em rede: a era da informação - economia, sociedade e cultura, Rio de Janeiro, Paz e Terra, 1999(1).

[6] Dowbor, L., Parcerias e alianças: o bom senso na gestão social: uma abordagem conceitual das políticas para crianças e adolescentes, São Paulo, 2002, disponível em http://dowbor.org/parceriasfinal.doc, acesso em 20/05/2009.

[7] Drucker, P., Administração de organizações sem fins lucrativos: princípios e práticas, São Paulo, Pioneira, 1994.

[8] Emirbayer, M. , Manifesto for a relational sociology, American Journal of Sociology, 1997, 103 (2).

[9] Estatuto, Obra Nossa Senhora da Glória - Fazenda da Esperança, Guaratinguetá, 2003.

[10] Fleury, S., Overney, A.M., Gestão de redes: a estratégia de regionalização da política de saúde, Rio de Janeiro, Editora FGV, 2007.

[11] Foucault, M., Microfísica do poder, Rio de Janeiro, Graal, 2005:35.

[12] Goldenberg, M., A arte de pesquisar - como fazer pesquisa qualitativa em ciências sociais, Rio de Janeiro, Record, 2007.

[13] Granovetter, M. S., The strength of weak ties, American Journal of Sociology, may 1973, 78 (6), 1360-1380.

[14] Gulati, R., Gargiulo, M., Where do interorganizational networks come from ?, American Journal of Sociology, mar. 1999, 104 (5), 1439-1493.

[15] Hakanson, H., Industrial technological development: a network approach, London, Routledge, 1987.

[16] Inojosa, R., Junqueira, L. A. P., O setor saúde e o desafio da intersetorialidade, São Paulo, Cadernos FUNDAP, 1997, 21, 156-154.

[17] Inojosa, R., Junqueira, L. A. P., Desenvolvimento social e intersetorialidade: a cidade solidária, São Paulo, Cadernos FUNDAP, 1997.

[18] Junqueira, L. A. P., A gestão intersetorial das políticas sociais e o terceiro setor, Saúde e Sociedade, jan./abr. 2004, 13 (1), 25-36.

[19] Junqueira, L. A. P., Intersetorialidade, transetorialidade e redes sociais na saúde, Rio de Janeiro, In RAP - Revista de Administração Pública, nov. / dez. 2000, 34 (66), 35-45. 
[20] Junqueira, L. A. P., Organizações sem fins lucrativos e redes sociais na gestão das políticas sociais, In Cavalcanti, M. (org.), Gestão social, estratégias e parcerias redescobrindo a essência da administração brasileira de comunidades para o Terceiro Setor, São Paulo, Saraiva, 2008.

[21] Junqueira, L. A. P., O terceiro setor e a gestão das organizações sem fins lucrativos, Ceará, Juazeiro do Norte, In: Anais do Encontro Nacional de Pesquisadores em Gestão Social, 2007.

[22] Lopes, F. D., Baldi, M., Laços sociais e formação de arranjos organizacionais cooperativos - proposição de um modelo de análise, In RAC - Revista de Administração Contemporânea, abr. / jun. 2005, 9 (2), 81-101.

[23] Marconi, M. A., Lakatos, E. M., Metodologia cientifica, São Paulo, Atlas, 2004.

[24] Marteleto, R. M., Analysis of social networks - application in the studies of information transfer, Ciência da Informação, jan. / abr. 2001, 30(1).

[25] Mizruchi, M. S., Análise de redes sociais: avanços recentes e controvérsias atuais, In RAE - Revista de Administração de Empresas, jul. / set. 2006, 46(3), 72-86.

[26] Mynayo, M. C. S., Deslantes, S. F., Gomes, R., Pesquisa social - teoria, método e criatividade, Petrópolis, Vozes, 2007.

[27] Portugal, S., As coisas, os modos e os laços: o papel das redes informais na provisão de recursos, Actas dos ateliers do V Congresso Português de Sociologia Sociedades Contemporâneas, Reflexividade e Acção Atelier: Famílias, 2004.

[28] Prigogine, I., O fim das certezas: tempo, caos e as leis da natureza, São Paulo, UNESP, 1996.

[29] Prigogine, I., O fim das certezas. In: MENDES, C. (org.), Representação e complexidade, Rio de Janeiro, Garamond, 2003.

[30] Quivy, R., Champenhoudt, L. V., Manual de investigação em Ciências Sociais, Lisboa, Gradiva, 2003.

[31] Raud-Mattedi, C., Análise crítica da sociologia econômica de Mark Granovetter: os limites de uma leitura do mercado em termos de redes e imbricação, abr. 2005:67, disponível em: www.periodicos.ufsc.br, acesso em 01/05/2009.

[32] Relatório anual de atividades sociais, Obra Social Nossa Senhora da Glória Fazenda da Esperança, 2007.

Revista Administração em Diálogo 
[33] Rico, E. M., A filantropia empresarial e sua inserção no Terceiro Setor, In Cavalcanti, M. (org.), Gestão social, estratégias e parcerias - redescobrindo a essência da administração brasileira de comunidades para o Terceiro Setor, São Paulo, Saraiva, 2008.

[34] Rico, E.M., Raichelis, R. (orgs.), Gestão social - uma questão em debate, São Paulo, EDUC, 1999.

[35] Rossoni, L., Silva, A. J. H. da, Ferreira Júnior, I., Aspectos estruturais da cooperação entre pesquisadores no campo de administração pública e gestão social: análise das redes entre instituições no Brasil, In RAP - Revista de Administração Pública, nov. / dez. 2008, 42 (6), 1041-1067.

[36] Santos, C. A., Bruschke, K., Da esquina para o mundo - o que são as Fazendas da Esperança, São Paulo, Cidade Nova, 2007.

[37] Siqueira, M. M., Redes sociais na gestão de serviços urbanos, In RAP - Revista de Administração Pública, nov. / dez. 2000, 34 (6), 98-179.

[38] Teixeira, C. S., Tatebuias - histórias reais daqueles que se livraram das drogas na Fazenda da Esperança, São Paulo, Cidade Nova, 2001.

[39] Tobar, F., Pardo, C. A. F., Organizaciones solidarias: gestión e innovación em el Tercer Setor, Buenos Aires, Lugar Editorial, 2000.

[40] Tomaél, M. I., Marteleto, R. M., Redes sociais: posição dos atores no fluxo da informação, Revista Eletrônica Bibliotecon, 2006, $\mathrm{n}^{\circ}$ especial, disponível em www.periodicos.ufsc.br/index.php/eb/article/download/342/387, acesso em 01/06/2009.

[41] Wanderley, L. E. W., Castel, R., Belfiore-Wanderley, M., Desigualdade e a questão social, São Paulo, EDUC, 2008.

[42] Weisbrot, M. et. al., Growth may be good for the poor - but are the IMF and world bank policies good for growth ? A closer look at the world bank's most recent defense of its policies, Washington, Centre for Economic and Policy Research, 2000.

[43] Wilheim, J., In Rico, E. M., Raichelis, R. (orgs.), Gestão social, uma questão em debate, São Paulo, EDUC, 1999.

[44] Zancan, L. A. P., As contribuições teóricas da análise de redes sociais aos estudos organizacionais, In XXXII ENANPAD, Rio de Janeiro, set. 2008. 